University of Wollongong

Research Online

Faculty of Engineering and Information

Faculty of Engineering and Information

Sciences - Papers: Part A

Sciences

$1-1-2013$

\title{
Removal of trace organic contaminants by the forward osmosis process
}

\author{
Abdulhakeem Alturki \\ University of Wollongong, ahaa572@uowmail.edu.au \\ James McDonald \\ University of New South Wales \\ Stuart Khan \\ University of New South Wales, s.khan@unsw.edu.au \\ William Price \\ University of Wollongong, wprice@uow.edu.au \\ Long Nghiem \\ University of Wollongong, longn@uow.edu.au
}

See next page for additional authors

Follow this and additional works at: https://ro.uow.edu.au/eispapers

Part of the Engineering Commons, and the Science and Technology Studies Commons

Research Online is the open access institutional repository for the University of Wollongong. For further information contact the UOW Library: research-pubs@uow.edu.au 


\title{
Removal of trace organic contaminants by the forward osmosis process
}

\begin{abstract}
The rejection of trace organic contaminants (TrOCs) by an osmotically driven membrane filtration process was investigated. A set of 40 compounds representing major groups of TrOCs of concern was selected for this study. The rejection of the TrOCs by a commercial cellulose acetate asymmetric forward osmosis membrane, as well as a "tight" commercial thin-film composite nanofiltration (NF) membrane, was systematically investigated and compared under three different operating modes: forward osmosis (FO), pressure retarded osmosis (PRO) and reverse osmosis (RO). Results revealed that the cellulose acetate membrane had considerably smaller water and salt permeabilities as well as less negative surface charge compared to the NF membrane. However, the cellulose acetate membrane resulted in considerably higher water flux than the NF when operated in FO and PRO modes. Nevertheless, the NF membrane displayed consistently better TrOC rejection than the HTI membrane. In RO mode, electrostatic interactions played a dominant role in governing the rejection of charged TrOCs. In FO and PRO modes, the rejection of charged TrOCs was governed by both electrostatic interaction and size exclusion, while rejection of neutral compounds was dominated by size exclusion, with rejection increasing with TrOC molecular weight. Operating in PRO mode resulted in a higher water flux but a notably lower TrOC rejection as compared with FO mode, because of more severe internal concentration polarization (ICP) phenomenon. Another important observation from this study is that rejection of neutral TrOCs in FO mode was higher than that in RO mode. This could be attributed to the retarded forward diffusion of TrOCs resulting from reverse salt flux of the $\mathrm{NaCl}$ draw solution, a phenomenon that takes place in $\mathrm{FO}$ mode but is not possible in RO mode.
\end{abstract}

\section{Keywords}

contaminants, osmosis, process, organic, trace, removal, forward

Disciplines

Engineering | Science and Technology Studies

\section{Publication Details}

Alturki, A. Ali., McDonald, J. A., Khan, S. J., Price, W. E., Nghiem, L. D. \& Elimelech, M. (2013). Removal of trace organic contaminants by the forward osmosis process. Separation and Purification Technology, 103 258-266.

\section{Authors}

Abdulhakeem Alturki, James McDonald, Stuart Khan, William Price, Long Nghiem, and Menachem Prof Menachem Elimelech 


\title{
Removal of trace organic contaminants by the forward osmosis process
}

\author{
Revised Manuscript Submitted to \\ Separation Purification Technology
}

Oct 2012

\author{
Abdulhakeem Ali Alturki ${ }^{1}$, James A. McDonald ${ }^{2}$, Stuart J. Khan ${ }^{2}$, William E. Price ${ }^{3}$, \\ Long D. Nghiem ${ }^{1, *}$, and Menachem Elimelech ${ }^{4}$ \\ ${ }^{1}$ Strategic Water Infrastructure Laboratory \\ School of Civil, Mining and Environmental Engineering \\ University of Wollongong, NSW 2522, Australia \\ ${ }^{2}$ Water Research Centre \\ The University of New South Wales, Sydney, NSW 2052, Australia \\ ${ }^{3}$ Strategic Water Infrastructure Laboratory, School of Chemistry \\ University of Wollongong, NSW 2522, Australia \\ ${ }^{4}$ Department of Chemical \& Environmental Engineering \\ Yale University, New Haven, Connecticut 06520-8286, USA
}

* Corresponding author: Long Duc Nghiem, Email: longn@uow.edu.au, Ph +61 242214590 


\section{Abstract}

The rejection of trace organic contaminants (TrOCs) by an osmotically driven membrane filtration process was investigated. A set of 40 compounds representing major groups of TrOCs of concern was selected for this study. The rejection of the TrOCs by a commercial cellulose acetate asymmetric forward osmosis membrane, as well as a "tight" commercial thin-film composite nanofiltration (NF) membrane, was systematically investigated and compared under three different operating modes: forward osmosis (FO), pressure retarded osmosis (PRO) and reverse osmosis (RO). Results revealed that the cellulose acetate membrane had considerably smaller water and salt permeabilities as well as less negative surface charge compared to the NF membrane. However, the cellulose acetate membrane resulted in considerably higher water flux than the NF when operated in FO and PRO modes. Nevertheless, the NF membrane displayed consistently better TrOC rejection than the HTI membrane. In RO mode, electrostatic interactions played a dominant role in governing the rejection of charged TrOCs. In FO and PRO modes, the rejection of charged TrOCs was governed by both electrostatic interaction and size exclusion, while rejection of neutral compounds was dominated by size exclusion, with rejection increasing with TrOC molecular weight. Operating in PRO mode resulted in a higher water flux but a notably lower TrOC rejection as compared with FO mode, because of more severe internal concentration polarization (ICP) phenomenon. Another important observation from this study is that rejection of neutral TrOCs in FO mode was higher than that in RO mode. This could be attributed to the retarded forward diffusion of TrOCs resulting from reverse salt flux of the $\mathrm{NaCl}$ draw solution, a phenomenon that takes place in FO mode but is not possible in RO mode.

Keywords: trace organic contaminants (TrOCs), forward osmosis, nanofiltration, retarded forward osmosis, rejection mechanisms. 


\section{Introduction}

Water and energy shortages are two of the most pervasive issues hindering economic growth in both developed and developing economies [1]. Not surprisingly, there has been a surge in the development and deployment of new technologies to support growth beyond the traditional limitations of natural resources [1]. The overarching aim of these new technologies is to reduce the carbon footprint associated with water production, while maximizing water recovery. Among these emerging technologies, forward osmosis (FO) has recently received increased attention as one that could potentially address these criteria [2-4].

In the FO process, a water-permeable and salt-rejecting membrane is placed between a feed solution, (which has a low concentration of inorganic salts but can be severely contaminated with organic pollutants or pathogenic agents), and a draw solution (which contains a specific salt such as $\mathrm{NaCl}$ at a high concentration that generates a high osmotic pressure) [4]. The natural osmosis process drives water to permeate through the membrane from the less concentrated 'feed solution' to the more concentrated 'draw solution'. Recent research has demonstrated that the FO process is not as susceptible to membrane fouling as other pressure driven membrane processes [5-6]. Even when fouling occurs, effective membrane cleaning can be achieved with little or no chemical treatment [5]. After extracting water from the feed solution, the draw solution is separated into two streams: a concentrated draw solution, which is recycled back to the membrane system to facilitate continuous FO operation, and freshwater, as the desired product. The draw solution can be recovered using a diverse range of separation processes, such as reverse osmosis (RO) or membrane distillation.

In theory, recovering the draw solution is an energy intensive process. However, in the case of membrane distillation, it is possible to utilize waste heat or solar thermal, and thus, the carbon footprint of the overall treatment process can remain very low. In another example, an FO desalination process using ammonia-carbon dioxide as the draw solute has recently been proposed [7]. Ammonium carbonate has a very high osmotic pressure and this draw solute can be regenerated using low grade heat (at approximately $60^{\circ} \mathrm{C}$ ) to recover the dissolved gases (i.e. ammonia and carbon dioxide), leaving behind clean product water [7]. In addition, FO does not require draw solution recovery in all cases. If a draw solute is used that adds value to the extracted water, the diluted draw solution can be used as it is, and new draw solutes can be introduced to the system to create additional product [4]. Examples of this include commercially 
available personal hydration packs, which use a sugar-and-nutrient draw solution to provide energy-boosting drinks from natural waters [4], or water used in irrigation, for which fertilizer serves as the draw solute, thus allowing the product water to be directly applied [8]. Alternatively, in an osmotic membrane bioreactor system [9-11] used to ensure high quality effluent discharge into the ocean, seawater can be used as the draw solution in a once-through fashion.

In several applications of the FO process, the removal of trace organic contaminants (TrOCs) that may occur in the contaminated feed water is an important consideration [12-15]. Many TrOCs, including steroid hormones and pharmaceutically active compounds, are continuously excreted by humans and other mammals and can directly enter the sewage system. However, the fate and transport of TrOCs during FO treatment is not fully understood.

To date, only a few studies relating to the rejection of TrOCs by FO membranes have been reported. A recent study by Hancock et al. [16] investigating the rejection of over 30 TrOCs by the FO process showed that their rejection was in the range of 40 to $98 \%$. In their study, more than $80 \%$ of charged compounds were rejected. However, the rejection of non-ionic compounds, at between 40 and 90\%, was highly variable. With the exception of tris (2-chloroethyl) phosphate, the rejection of non-ionic compounds by the FO process appeared to be governed by steric hindrance as shown by the trend of rejection increasing with increasing molecular weight [16]. Linares et al. [15] investigated the rejection of 13 TrOCs by a similar FO membrane using seawater from the Red Sea as the draw solution. Their results are also consistent with those reported by Hancock et al. [16]. Rejection of hydrophilic ionic contaminants, including ibuprofen, naproxen, fenoprofen, gemfibrozil and ketoprofen, was between 92.9 and 98.6\%. On the other hand, rejection of neutral compounds (e.g. caffeine, 1,4-dioxane, acetaminophen, metronidazole, phenazone, bisphenol A) varied significantly from 40 to $95.2 \%$ [15]. The rejection of the steroid hormones estrone and 17 $\alpha$-estradiol by an FO membrane has also been investigated by Cartinella et al. [17]. Their findings showed that when using different $\mathrm{NaCl}$ draw solution concentrations, estrone and $17 \alpha$-estradiol rejection varied from 77 to $99 \%$, depending on composition of the feed and experiment duration [17].

In this study, we examined the rejection of 40 TrOCs by a commercial membrane specifically designed for FO applications and a typical nanofiltration membrane. Rejection of the selected TrOCs was related to the membrane characteristics and mode of operation in order to 
systematically elucidate the underlying separation mechanisms. The results provide further insight into the rejection of TrOCs by the FO process and can potentially be useful for future design of FO membranes as well as optimization of the FO process.

\section{Materials and Methods}

\subsection{FO and NF membranes}

An FO membrane supplied by Hydration Technology Innovations (Albany, Oregon, USA) was used in this study. As described by McCutcheon et al. [18], it is an asymmetric cellulose acetate membrane, with a thin polyester mesh embedded within the porous supporting layer to provide mechanical strength. The dense cellulose acetate top layer is wholly responsible for solute separation and the membrane can be used in two different modes, namely FO and PRO. In FO mode, the dense (skin) layer of the membrane faces the feed solution, whereas in PRO mode, the porous layer of the membrane faces the feed solution. The NF90 membrane supplied by Dow FilmTec (Minneapolis, MN, USA) was selected to represent a nanofiltration membrane because it has comparable $\mathrm{NaCl}$ rejection to that of the FO membrane. NF90 is a thin-film composite membrane with a thin aromatic polyamide active layer on top of a thick and porous polysulphone supporting layer.

\subsection{Model trace organic contaminants}

A set of 40 compounds was chosen to represent four major trace organic groups of concern in water reuse applications: pharmaceutically active compounds, steroid hormones, industrial compounds, and pesticides. The selection of these model trace organic compounds was also based on their widespread occurrence in domestic sewage and their diverse physicochemical properties (e.g. ionisable versus non-ionisable, hydrophobicity and molecular size). Key physicochemical properties of these compounds are shown in Table 1. The selected trace contaminants included organic compounds with molecular weights in the range between 138.1 $\mathrm{g} / \mathrm{mol}$ (salicylic acid) and $454.6 \mathrm{~g} / \mathrm{mol}$ (verapamil). The intrinsic hydrophobicities of these

compounds vary significantly as reflected by their octanol-water partitioning coefficient (log $\mathrm{K}_{\mathrm{ow}}$ ) values. Possessing a number of different functional groups, many of these compounds are ionisable at environmental $\mathrm{pH}$. All of the trace organic compounds were purchased as analytical grade standards. A cocktail stock solution of the compounds was prepared in pure acetonitrile. It was kept in a freezer at $-18{ }^{\circ} \mathrm{C}$ and used within one month. 


\section{[TABLE 1]}

\subsection{Trace organic compound analysis}

Analysis of the TrOCs was based on a previously developed method [19]. In summary, target compounds were extracted using hydrophilic/lipophilic balance solid phase extraction (SPE) cartridges (Waters, Milford, MA, USA). All samples were spiked with a solution containing 50 ng of an isotopically labeled version of each analyte to account for any variation in recovery that may occur during the sample preparation process. Loaded cartridges were eluted with $5 \mathrm{~mL}$ of methanol followed by $5 \mathrm{~mL}$ of $1 / 9(\mathrm{v} / \mathrm{v})$ methanol/MTBE into centrifuge tubes. The resulting extracts were concentrated using vacuum assisted evaporation to approximately $100 \mu \mathrm{L}$. The extracts were brought to a final volume of $1 \mathrm{~mL}$ with methanol.

Target compounds were separated using an Agilent 1200 series high performance liquid chromatography (HPLC) system (Palo Alto, CA, USA) equipped with a $150 \mathrm{~mm}$ x $4.6 \mathrm{~mm}$, 5$\mu \mathrm{m}$ particle size, Luna C18 (2) column (Phenomenex, Torrance CA, USA). Analysis was conducted in both electrospray ionization (ESI) and atmospheric pressure chemical ionization (APCI) modes. A binary gradient consisting of $5 \mathrm{mM}$ ammonium acetate in water (A) and 100\% methanol (B) at a flow rate of $800 \mu \mathrm{L} / \mathrm{min}$ was used for TrOC analysis during ESI mode. For TrOC analysis using APCI, a binary gradient consisting of water (A) and $0.1 \%$ formic acid in methanol (B) at a flow rate of $500 \mu \mathrm{L} / \mathrm{min}$ was used. An injection volume of $10 \mu \mathrm{L}$ was used. Mass spectrometry was performed using an API 4000 triple quadrupole mass spectrometer (Applied Biosystems, Foster City, CA, USA) equipped with a turbo-V ion source employed in both positive and negative electro-spray modes. For each target compound and internal standard, a precursor ion and two product ions were monitored for reliable confirmation. Relative retention times of the analyte and isotopically labeled internal standards were also monitored to ensure correct identification. The detection limit of quantification of the 40 compounds selected was in the range from 5 to $20 \mathrm{ng} / \mathrm{L}$.

\subsection{Osmotically driven membrane system and experimental protocol}

Experiments were conducted using a laboratory-scale FO system consisting of a membrane cell, circulation pumps, a conductivity control device, and a temperature control unit (Figure 1). The membrane cell was able to hold a flat-sheet membrane under moderate pressure gradients without any physical support. The flow channels were engraved in each of the two Plexiglass 
blocks that made up the feed and draw solution semi-cells. Each channel was $0.2 \mathrm{~cm}$ deep, 10.5 $\mathrm{cm}$ wide, and $15.5 \mathrm{~cm}$ long. The total active membrane area for mass transfer was $162 \mathrm{~cm}^{2}$. Two gear pumps (Model 120/IEC71-B14, Micropump Inc., Vancouver, WA, USA) were used to circulate feed and draw solution from their respective reservoirs through the membrane cell and back. Analytical grade sodium chloride was used as the draw solute.

\section{[FIGURE 1]}

Before initiating the experiments, the TrOCs were spiked into a reservoir containing $4 \mathrm{~L}$ of MilliQ water to make up a concentration of $750 \mathrm{ng} / \mathrm{L}$ for each compound. The draw solution on the other side was circulated and weighed using an electronic balance (PB32002-S, Mettler-Toledo, Inc., Hightstown, NJ). The draw solution reservoir was equipped with a conductivity controller designed to activate a peristaltic pump to transfer near-saturated $\mathrm{NaCl}$ solution to the draw solution reservoir once the conductivity fell below a set point, thus maintaining a constant concentration of the $\mathrm{NaCl}$ draw solute. The conductivity and $\mathrm{pH}$ for both sides were checked and measured using an Orion 4-Star Plus pH/conductivity meter from Thermo-Scientific. Flow rates of the feed and draw solution were monitored using two rotameters and kept constant. The temperatures of the feed and draw solutions were maintained throughout the experiment at 22.5 $\pm 0.5^{\circ} \mathrm{C}$ using a temperature control unit (Neslab RTE 7, Thermo Fisher Scientific, Waltham, MA, USA) equipped with a stainless steel heat-exchanging coil, which was submerged in the feed and draw solution reservoirs. Samples $(500 \mathrm{~mL})$ of the feed and draw solution were taken for analysis at the beginning and, later, when $2 \mathrm{~L}$ of permeate had transferred into the draw solution (corresponding to $50 \%$ recovery).

Since the permeate sample was diluted using the initial draw solution, the dilution factor was calculated to back calculate the concentration of TrOC in the actual permeate sample. The dilution factor is defined as:

$\mathrm{DF}=\frac{V_{f, D S}}{V_{p}} \quad \mathrm{Eq} .1$

where $V_{f, D S}$ is the final volume of the draw solution and $V_{p}$ is the volume of the permeated water. Subsequently, the rejection of trace organics in the FO process can be calculated as:

$R(\%)=\left[1-\frac{\mathrm{DF} \times \mathrm{C}_{f, D S}}{\mathrm{C}_{\mathrm{F}_{0}}}\right] \times 100 \quad$ Eq. 2 
where $\mathrm{C}_{f, D S}$ is the final concentration of the trace organics in the draw solution, $\mathrm{C}_{\mathrm{F}_{0}}$ is the initial concentration of the trace organics in the feed solution, and DF is the dilution factor defined in Eq. 1 above.

\subsection{Pressure driven membrane filtration system and experimental protocol}

A laboratory-scale, cross-flow membrane filtration system with a stainless steel cross-flow cell

was used (Figure 2). The cell had an effective membrane area of $40 \mathrm{~cm}^{2}(4 \mathrm{~cm} \times 10 \mathrm{~cm})$ and a channel height of $2 \mathrm{~mm}$. The system was equipped with a Hydra-Cell pump (Wanner Engineering, Inc., Minneapolis, MN). The temperature of the test solution was kept constant using a Neslab RTE 7 chiller/heater equipped with a stainless steel heat exchanger coil that was submerged directly into a stainless steel reservoir. The permeate flow was measured by a digital flow meter (Optiflow 1000, Agilent Technologies, Palo Alto, CA) connected to a PC, and the cross-flow rate was monitored using a rotameter.

Prior to each pressure driven filtration experiment, the membrane was compacted using Milli-Q water for approximately 16 hours until there was no further variation in the permeate flux. The compacting pressures were 12 and 22 bars for the NF90 and FO membranes, respectively. TrOCs (750 ng/L of each) were then introduced to the feed reservoir. The volume of the feed solution was $10 \mathrm{~L}$. The cross-flow velocity was fixed at $30.4 \mathrm{~cm} / \mathrm{s}$ and the permeate flux was adjusted to 14.6 $\mathrm{L} / \mathrm{m}^{2} \mathrm{~h}$, which is half of the nominal permeate flux of the NF90 recommended by the manufacturer. The feed reservoir temperature was kept constant at $20 \pm 0.1{ }^{\circ} \mathrm{C}$ throughout the experiment. The permeate and concentrate were both recirculated back to the feed reservoir. Permeate and feed samples of $500 \mathrm{~mL}$ were collected after 25 hours of filtration and immediately extracted by SPE for analysis. The rejection was defined as $R=100 /\left(1-C_{\mathrm{P}} / C_{\mathrm{F}}\right)$, where $C_{\mathrm{P}}$ and $C_{\mathrm{F}}$ are the concentrations for the permeate and the feed trace organics, respectively.

\section{[FIGURE 2]}

\subsection{Membrane characterization}

\subsubsection{Determination of membrane active layer transport properties}

The intrinsic water permeability coefficient (often called the "A value") and salt permeability coefficient (often called the " $B$ value") of the membranes were characterized using the crossflow filtration system described in Section 2.5, according to a procedure described elsewhere [20-21]. First, the permeation rate of Milli-Q water was normalized by the membrane area to 
obtain the pure water flux $J_{\mathrm{w}}$. The $A$ value was then determined by dividing the water flux by the applied pressure $(\Delta P)$ :

$$
\mathrm{A}=\frac{J_{w}}{\Delta P} \quad \text { Eq. } 3
$$

To obtain the $B$ value, $2,000 \mathrm{mg} / \mathrm{L}$ of $\mathrm{NaCl}$ were introduced to the feed solution. The $B$ value of $\mathrm{NaCl}$ was determined after correcting for concentration polarization using the thin-film theory [20]:

$\mathrm{B}=J_{w}\left(\frac{1-R}{R}\right) e^{\left(-\frac{J_{W}}{k}\right)} \quad$ Eq. 4

where $k$ is the mass transfer coefficient for the channel of the RO cross-flow filtration system, $R$ is the observed rejection as defined in Section 2.5, and $J_{\mathrm{w}}$ is the pure water flux.

\subsubsection{Contact angle measurement}

Contact angle measurement of the membrane surfaces was conducted using a Ramé-Hart Goniometer (Model 250, Ramé-Hart, Netcong, NJ) following the standard sessile drop method. Milli-Q water was used as the reference solvent. The membranes were air dried prior to the measurement. At least 5 droplets were applied onto duplicate membrane samples and the contact angle was measured on both sides of the droplet.

\subsubsection{Zeta potential measurement}

The surface streaming potential of the membrane was measured using a SurPASS Electrokinetic Analyzer (Anton Paar GmbH, Graz, Austria) in a $1 \mathrm{mM} \mathrm{KCl}$ background solution. The Fairbrother-Mastin method was used to calculate the zeta potential from the measured streaming potential, which was performed at 500 mbar and at room temperature $\left(25 \pm 1^{\circ} \mathrm{C}\right)$. The zeta potential of each membrane sample was measured four times, by repeatedly reversing the direction of electrolyte flow at each $\mathrm{pH}$ value. Instrument error counted for less that $0.5 \mathrm{mV}$ of the measurement at any given $\mathrm{pH}$ value. Analytical grade potassium hydroxide and hydrochloric acid were used to adjust the $\mathrm{pH}$ by means of automatic titration.

\section{Results and discussion}

\subsection{Membrane characterization}

The active layers of the HTI and NF90 membranes are made of cellulose acetate and polyamide, respectively. Nevertheless, they have comparable hydrophobicity and average membrane pore 
size (Table 2). Because the HTI membrane is made with asymmetric cellulose acetate, its active and backing layers have an almost identical zeta potential as a function of $\mathrm{pH}$ (Figure 3). The isoelectric point of the HTI membrane is at approximately $\mathrm{pH} 4$, and at higher $\mathrm{pH}$, the membrane becomes slightly negatively charged. The NF90 membrane also has an isoelectric point at approximately $\mathrm{pH} 4$. However, at near neutral $\mathrm{pH}$ or above, it has a significantly more negative zeta potential than the HTI membrane.

Both $A$ and $B$ values (i.e. water and salt permeabilities) of the HTI membrane were significantly smaller than those of the NF90 membrane (Table 2), despite the former having a slightly larger membrane pore size. This behavior is in accordance with the structure of the selective barriers of these membranes, with the thin-film composite membrane having a much thinner polyamide active layer than the asymmetric cellulose acetate membrane [22]. Nevertheless, given that the NF90 membrane was not designed for use in osmotically driven membrane processes, its water flux was negligible (data not shown) in both FO and PRO modes, when a draw solution of $0.5 \mathrm{M}$ of $\mathrm{NaCl}$ was used. Only when $2 \mathrm{M} \mathrm{NaCl}$ was used as the draw solution in PRO mode, did the NF90 membrane produce a water flux of $0.2 \mathrm{~L} / \mathrm{m}^{2} \mathrm{~h}$ (Figure 4). In contrast, considerable water flux was obtained with the HTI membrane (Figure 4). The very low water flux observed with the NF90 membrane could be attributed to the structure and chemistry of the thick and hydrophobic polysulfone support layer, which results is severe internal concentration polarization (ICP) [2324]. Such significant effect of ICP can also be seen by comparing the water flux of the HTI membrane under FO and PRO modes. Since Milli-Q water was used as the feed, the concentrative ICP in PRO mode was less than the dilutive ICP in FO mode, resulting in higher water flux for the former case. However, it is noteworthy that the reverse salt flux was also higher in PRO mode when compared to FO mode. Results shown in Figures 4 and 5 also demonstrate that both the water and reverse salt fluxes increase as draw solution concentration increases.

[TABLE 2]

[FIGURE 3]

[FIGURE 4]

[FIGURE 5] 


\subsection{Rejection of trace organic contaminants}

The separation of TrOCs by a membrane filtration process can be governed by either electrostatic interaction or size exclusion or both [25-26]. At $\mathrm{pH} \mathrm{6}$, as used in this study, five

compounds (i.e. atenolol, trimethoprim, fluoxetine, clozapine, and hydroxyzine) were positively charged and eight other compounds were negatively charged. The remaining 27 investigated compounds existed predominantly in their neutral forms.

\subsubsection{Charged organic compounds}

The rejection of charged TrOCs in the PRO, FO and RO modes is presented in Figure 6. It is noteworthy that in PRO and FO modes, rejection values were determined at 50\% water recovery while the water recovery in RO mode was negligible.

In PRO mode, the rejection of most charged TrOCs by the NF90 membrane was considerably higher than that by the HTI FO membrane. This can be attributed to the fact that the NF90 membrane had a smaller pore size and significantly more negative zeta potential than the HTI membrane (Section 3.1). In addition to charge interaction, size exclusion can also play a major role in influencing the rejection of charged TrOCs by the HTI membrane, as seen by the increased rejection with increasing TrOC molecular weight. It is notable that the rejection of charged and small molecular weight TrOCs was higher when a $0.5 \mathrm{M} \mathrm{NaCl}$ was used as the draw solution compared to $2 \mathrm{M} \mathrm{NaCl}$. This can possibly be explained by the high reverse salt flux observed when $2 \mathrm{M} \mathrm{NaCl}$ was used, which resulted in a higher ionic strength within the support layer on the feed side of the HTI membrane. The enhanced ionic strength could reduce the effectiveness solute rejection by electrostatic interaction or the suppression of the double layer surrounding a charge solute, which results in lower rejection of charged species [27].

In FO mode, the rejection of charged and small molecular weight TrOCs was higher than that in PRO mode (Figure 6). In PRO mode, because water first permeates through the supporting layer and then the dense skin layer of the HTI membrane toward the draw solution side, the ICP of TrOCs can be very severe. This ICP phenomenon could explain the lower rejection of charged and small molecular weight TrOCs in PRO mode in comparison to FO mode.

In RO mode, since the ionic strength of the feed solution was negligible, rejection of charged TrOCs by both the HTI and NF90 membranes was high and dominated by electrostatic interaction. Rejection of all charged TrOCs by the NF90 was slightly higher than that by the HTI membrane, likely because of the smaller average pore size of the NF90 membrane active layer. 
The NF90 and HTI membranes were both negatively charged at the experimental pH used in this study ( $\mathrm{pH}$ 6). Nevertheless, the NF90 had a more negative zeta potential than either the active or backing layers of the HTI membrane (Figure 3). Results shown in Figure 6 suggest that electrostatic interaction was a dominant rejection mechanism for charged TrOCs in RO mode. However, electrostatic interaction appears to play a less important role in PRO and FO modes due to an increase in ionic strength caused by the reverse salt flux as discussed previously. As a result, the rejection of charged TrOCs by the HTI membrane in PRO and FO modes was considerably lower than that in RO mode (Figure 6).

\section{[FIGURE 6]}

\subsubsection{Neutral organic compounds}

In general, for all three modes (PRO, FO, and RO), the rejection of neutral TrOCs increased as their molecular weights increased (Figure 7). In addition, rejection of neutral TrOCs in FO mode was higher than that in PRO mode. This is because the ICP effect was more severe in PRO mode than in FO mode as previously discussed in Section 3.2.1. In the same mode of operation, the rejection of almost all neutral TrOCs by the NF90 membrane was higher than that by the HTI membrane. This again may be explained by the smaller pore size of the NF90 membrane compared to the HTI membrane (Table 2).

Rejection of neutral TrOCs in FO mode was notably higher than that in RO mode (Figure 7), despite the fact that the water flux obtained in FO mode was lower than that in RO mode. Unlike charged solutes, interactions between neutral solutes and the membrane are not influenced by ionic strength [28]. Thus, this observation cannot be attributed to the difference in ionic strength between RO and FO modes. Indeed, this interesting observation is consistent with the results previously reported by Xie et al. [14]. In RO mode, transport of neutral TrOCs across the membrane is concurrent with the flow of all other solutes. In FO mode, transport of water through the membrane is coupled with reverse salt flux (i.e. in the opposite direction). Reverse $\mathrm{NaCl}$ flux in the FO experiment was significant (Figure 5). In addition, the hydrated radii of $\mathrm{Na}^{+}$ $(0.36 \mathrm{~nm})$ and $\mathrm{Cl}^{-}(0.33 \mathrm{~nm})$ [29] were comparable to that of the membrane pore radius. As a result, reverse salt flux could hinder pore forward diffusion of the TrOCs, leading to higher rejection in FO mode than in $\mathrm{RO}$ mode.

[FIGURE 7] 


\section{Conclusion}

The rejection of 40 TrOCs by FO (HTI) and NF (NF90) membranes was investigated. Detailed membrane characterization revealed that the HTI membrane, a commercially available membrane specifically designed for osmotically driven membrane applications, has considerably smaller water and salt permeabilities as well as less negative zeta potential than the NF90, a typical nanofiltration membrane. While the HTI membrane enabled considerably higher water flux than the NF90 when operated in the osmotically driven configuration, the NF90 consistently showed better rejection of TrOCs than the HTI membranes. In RO mode, electrostatic interaction played a dominant role in governing the rejection of charged TrOCs. In FO and PRO modes, the rejection of charged TrOCs was governed by both electrostatic interaction and size exclusion. In the absence of electrostatic interaction, the rejection of neutral compounds was dominated by size exclusion and the rejection increased as the molecular weights of the TrOCs increased. The PRO mode resulted in higher water flux but notably lower TrOC rejection when compared to FO mode. These observations can be explained by the severe ICP of TrOCs in PRO mode. Also interesting to note is the fact that rejection of neutral TrOCs in FO mode was higher than that in RO mode. This is caused by the retarded forward diffusion of TrOCs, which occurs in FO mode when the reverse salt flux is significant but not in RO mode.

\section{Acknowledgements}

The Saudi Arabian Cultural Mission in Australia is acknowledged for providing a $\mathrm{PhD}$ scholarship to Abdulhakeem Ali Alturki. Hydration Technology Innovations (Albany, Oregon, USA) and Dow FilmTec (Minneapolis, MN) are thanked for the provision of membrane samples.

\section{References}

[1] Shannon, M.A., Bohn, P.W., Elimelech, M., Georgiadis, J.G., Marinas, B.J., and Mayes, A.M., Science and technology for water purification in the coming decades. Nature, 2008. 452(7185): p. 301-310.

[2] Zhao, S., Zou, L., Tang, C.Y., and Mulcahy, D., Recent developments in forward osmosis: Opportunities and challenges. Journal of Membrane Science, 2012. 396(0): p. 121.

[3] Cath, T.Y., Childress, A.E., and Elimelech, M., Forward osmosis: Principles, applications, and recent developments. Journal of Membrane Science, 2006. 281(1-2): p. 70. 
[4] Hoover, L.A., Phillip, W.A., Tiraferri, A., Yip, N.Y., and Elimelech, M., Forward with Osmosis: Emerging Applications for Greater Sustainability. Environmental Science and Technology, 2011. 45(23): p. 9824-9830.

[5] Mi, B. and Elimelech, M., Organic fouling of forward osmosis membranes: Fouling reversibility and cleaning without chemical reagents. Journal of Membrane Science, 2010. 348(1-2): p. 337-345.

[6] Lee, S., Boo, C., Elimelech, M., and Hong, S., Comparison of fouling behavior in forward osmosis (FO) and reverse osmosis (RO). Journal of Membrane Science, 2010. 365(1-2): p. 34-39.

[7] McCutcheon, J.R., McGinnis, R.L., and Elimelech, M., A novel ammonia--carbon dioxide forward (direct) osmosis desalination process. Desalination, 2005. 174(1): p. 111.

[8] Phuntsho, S., Shon, H.K., Hong, S., Lee, S., Vigneswaran, S., and Kandasamy, J., Fertiliser drawn forward osmosis desalination: The concept, performance and limitations for fertigation. Reviews in Environmental Science and Biotechnology, 2012. 11(2): p. 147-168.

[9] Alturki, A., McDonald, J., Khan, S.J., Hai, F.I., Price, W.E., and Nghiem, L.D., Performance of a novel osmotic membrane bioreactor (OMBR) system: Flux stability and removal of trace organics. Bioresource Technology, 2012. 113(0): p. 201-206.

[10] Qin, J.J., Oo, M.H., Tao, G., Cornelissen, E.R., Ruiken, C.J., de Korte, K.F., Wessels, L.P., and Kekre, K.A., Optimization of operating conditions in forward osmosis for osmotic membrane bioreactor. Open Chemical Engineering Journal, 2009. 3: p. 27-32.

[11] Achilli, A., Cath, T.Y., Marchand, E.A., and Childress, A.E., The forward osmosis membrane bioreactor: A low fouling alternative to MBR processes. Desalination, 2009. 239(1-3): p. 10-21.

[12] Hancock, N.T., Xu, P., Heil, D.M., Bellona, C., and Cath, T.Y., Comprehensive Benchand Pilot-Scale Investigation of Trace Organic Compounds Rejection by Forward Osmosis. Environmental Science and Technology, 2011. 45(19): p. 8483-8490.

[13] Xie, M., Price, W.E., and Nghiem, L.D., Rejection of pharmaceutically active compounds by forward osmosis: Role of solution $\mathrm{pH}$ and membrane orientation. Separation and Purification Technology, 2012. 93(0): p. 107-114.

[14] Xie, M., Nghiem, L.D., Price, W.E., and Elimelech, M., Comparison of the removal of hydrophobic trace organic contaminants by forward osmosis and reverse osmosis. Water Research, 2012. 46(8): p. 2683-2692.

[15] Valladares Linares, R., Yangali-Quintanilla, V., Li, Z., and Amy, G., Rejection of micropollutants by clean and fouled forward osmosis membrane. Water Research, 2011. 45(20): p. 6737-6744. 
[16] Hancock, N.T., Xu, P., Heil, D.M., Bellona, C., and Cath, T.Y., Comprehensive Benchand Pilot-Scale Investigation of Trace Organic Compounds Rejection by Forward Osmosis. Environmental Science \& Technology, 2011. 45(19): p. 8483-8490.

[17] Cartinella, J.L., Cath, T.Y., GMiller, G.C., Hunter, K.e.W.J.R., and Childress, A.E., Removal of Natural Steroid Hormones from Wastewater Using Membrane Contactor Processes. Environ. Sci. Technol. , 2006. 40: p. 7381-7386.

[18] McCutcheon, J.R., McGinnis, R.L., and Elimelech, M., Desalination by ammonia-carbon dioxide forward osmosis: Influence of draw and feed solution concentrations on process performance. Journal of Membrane Science, 2006. 278(1-2): p. 114-123.

[19] Tadkaew, N., Hai, F.I., McDonald, J.A., Khan, S.J., and Nghiem, L.D., Removal of trace organics by MBR treatment: the role of molecular properties. Water Research, 2011. 45(8): p. 2439-2451.

[20] T.Y. Cath, Elimelech, M., McCutcheon, J.R., McGinnis, R.L., Achilli, A., Anastasio, D., Brady, A.R., Childress, A.E., Farr, I.V., Hancock, N.T., Lampi, J., Nghiem, L.D., Yip, N.Y., and Xie, M., Standard Methodology for Evaluating Membrane Performance in Osmotically Driven Membrane Processes. Desalination, Submitted.

[21] Tiraferri, A., Yip, N.Y., Phillip, W.A., Schiffman, J.D., and Elimelech, M., Relating performance of thin-film composite forward osmosis membranes to support layer formation and structure. Journal of Membrane Science, 2011. 367(1-2): p. 340-352.

[22] Freger, V., Gilron, J., and Belfer, S., TFC polyamide membranes modified by grafting of hydrophilic polymers: an FT-IR/AFM/TEM study. Journal of Membrane Science, 2002. 209(1): p. 283-292.

[23] McCutcheon, J.R. and Elimelech, M., Influence of membrane support layer hydrophobicity on water flux in osmotically driven membrane processes. Journal of Membrane Science, 2008. 318(1-2): p. 458-466.

[24] McCutcheon, J.R. and Elimelech, M., Influence of concentrative and dilutive internal concentration polarization on flux behavior in forward osmosis. Journal of Membrane Science, 2006. 284(1-2): p. 237-247.

[25] Nghiem, L.D., Schäfer, A.I., and Elimelech, M., Pharmaceutical Retention Mechanisms by Nanofiltration Membranes. Environmental Science \& Technology, 2005. 39(19): p. 7698-7705.

[26] Verliefde, A., Cornelissen, E., Amy, G., Van der Bruggen, B., and van Dijk, H., Priority organic micropollutants in water sources in Flanders and the Netherlands and assessment of removal possibilities with nanofiltration. Environmental Pollution, 2007. 146(1): p. 281-289.

[27] Nghiem, L.D., Schafer, A.I., and Elimelech, M., Role of electrostatic interactions in the retention of pharmaceutically active contaminants by a loose nanofiltration membrane. Journal of Membrane Science, 2006. 286(1-2): p. 52-59. 
[28] Nghiem, L.D., Schaffer, A.I., and Elimelech, M., Nanofiltration of hormone mimicking trace organic contaminants. Separation Science and Technology, 2005. 40(13): p. 26332649.

[29] Israelachvili, J.N., Intermolecular and Surface Forces. Second ed. In: With Applications to Colloidal and Biological Systems. 2010: Academic Press.

[30] Nghiem, L.D., Schäfer, A.I., and Elimelech, M., Removal of Natural Hormones by Nanofiltration Membranes: Measurement, Modeling, and Mechanisms. Environmental Science \& Technology, 2004. 38: p. 1888-1896. 
Table 1: Summary of relevant physiochemical properties of the selected TrOCs.

\begin{tabular}{|c|c|c|c|c|c|c|}
\hline Compound & CAS no. & MW (g/mol) & $\log K_{\mathrm{ow}}$ & Charge* & $p K_{a}$ & Formula \\
\hline Salicylic acid & 69-72-7 & 138.12 & 2.01 & - & 3.01 & $\mathrm{C}_{7} \mathrm{H}_{6} \mathrm{O}_{3}$ \\
\hline Paracetamol & $103-90-2$ & 151.16 & 0.47 & $\mathrm{n}$ & $9.86 ; 1.72$ & $\mathrm{C}_{8} \mathrm{H}_{9} \mathrm{NO}_{2}$ \\
\hline Polyparaben & $94-13-3$ & 180.2 & 2.9 & $\mathrm{n}$ & 8.23 & $\mathrm{C}_{10} \mathrm{H}_{12} \mathrm{O}_{3}$ \\
\hline Caffeine & $58-08-2$ & 194.19 & -0.63 & $\mathrm{n}$ & 0.52 & $\mathrm{C}_{8} \mathrm{H}_{10} \mathrm{~N}_{4} \mathrm{O}_{2}$ \\
\hline Ibuprofen & $15687-27-1$ & 206.28 & 3.5 & - & 4.41 & $\mathrm{C}_{13} \mathrm{H}_{18} \mathrm{O}_{2}$ \\
\hline Primidone & $125-33-7$ & 218.25 & 0.83 & $\mathrm{n}$ & $12.26 ;-1.07$ & $\mathrm{C}_{12} \mathrm{H}_{14} \mathrm{~N}_{2} \mathrm{O}_{2}$ \\
\hline Meprobamate & $57-53-4$ & 218.25 & 0.7 & $\mathrm{n}$ & $13.09 ;-1.09$ & $\mathrm{C}_{9} \mathrm{H}_{18} \mathrm{~N}_{2} \mathrm{O}_{4}$ \\
\hline Naproxen & 22204-53-1 & 230.26 & 2.88 & - & 4.84 & $\mathrm{C}_{14} \mathrm{H}_{14} \mathrm{O}_{3}$ \\
\hline Gemfibrozil & 25812-30-0 & 250.33 & 4.3 & - & 4.75 & $\mathrm{C}_{15} \mathrm{H}_{22} \mathrm{O}_{3}$ \\
\hline Dilantin & 57-41-0 & 252.27 & 1.42 & $\mathrm{n}$ & $8.28 ;-2.81$ & $\mathrm{C}_{15} \mathrm{H}_{12} \mathrm{~N}_{2} \mathrm{O}_{2}$ \\
\hline Triamterene & $396-01-0$ & 253.26 & 1.16 & - & 6.28 & $\mathrm{C}_{12} \mathrm{H}_{11} \mathrm{~N}_{7}$ \\
\hline Ketoprofen & 22071-15-4 & 254.28 & 2.91 & - & 4.23 & $\mathrm{C}_{16} \mathrm{H}_{14} \mathrm{O}_{3}$ \\
\hline Atenolol & 29122-68-7 & 266.34 & 0.33 & + & $13.88 ; 9.43$ & $\mathrm{C}_{14} \mathrm{H}_{22} \mathrm{~N}_{2} \mathrm{O}_{3}$ \\
\hline Amitriptyline & 50-48-6 & 277.4 & 4.41 & $\mathrm{n}$ & 9.18 & $\mathrm{C}_{20} \mathrm{H}_{23} \mathrm{~N}$ \\
\hline Triclosan & $3380-34-5$ & 289.54 & 5.34 & $\mathrm{n}$ & 7.8 & $\mathrm{C}_{12} \mathrm{H}_{7} \mathrm{Cl}_{3} \mathrm{O}_{2}$ \\
\hline Trimethoprim & $738-70-5$ & 290.32 & 0.59 & + & 7.04 & $\mathrm{C}_{14} \mathrm{H}_{18} \mathrm{~N}_{4} \mathrm{O}_{3}$ \\
\hline Diclofenac & $15307-86-5$ & 296.15 & 4.55 & - & $4.18 ;-2.26$ & $\mathrm{C}_{14} \mathrm{H}_{11} \mathrm{Cl}_{2} \mathrm{NO}_{2}$ \\
\hline Fluoxetine & $54910-89-3$ & 309.33 & 3.93 & + & 10.05 & $\mathrm{C}_{17} \mathrm{H}_{18} \mathrm{~F}_{3} \mathrm{NO}$ \\
\hline Triclocarban & $101-20-2$ & 315.58 & 6.07 & $\mathrm{n}$ & $12.77 ;-0.34$ & $\mathrm{C}_{13} \mathrm{H}_{9} \mathrm{Cl}_{3} \mathrm{~N}_{2} \mathrm{O}$ \\
\hline Clozapine & $5786-21-0$ & 326.82 & 3.94 & + & 7.33 & $\mathrm{C}_{18} \mathrm{H}_{19} \mathrm{ClN}_{4}$ \\
\hline Omeprazole & $73590-58-6$ & 345.42 & 2.36 & $\mathrm{n}$ & $8.78 ; 4.72$ & $\mathrm{C}_{17} \mathrm{H}_{19} \mathrm{~N}_{3} \mathrm{O}_{3} \mathrm{~S}$ \\
\hline Hydroxyzine & $68-88-2$ & 374.9 & 2.32 & + & $14.41 ; 6.62$ & $\mathrm{C}_{21} \mathrm{H}_{27} \mathrm{ClN}_{2} \mathrm{O}_{2}$ \\
\hline Risperidone & 106266-06-2 & 410.48 & 2.68 & $\mathrm{n}$ & 8.07 & $\mathrm{C}_{23} \mathrm{H}_{27} \mathrm{FN}_{4} \mathrm{O}_{2}$ \\
\hline Simvastatin & $79902-63-9$ & 418.57 & 4.72 & $\mathrm{n}$ & 13.49 & $\mathrm{C}_{25} \mathrm{H}_{38} \mathrm{O}_{5}$ \\
\hline Simvastatin hydroxy acid & $121009-77-6$ & 436.58 & 4.53 & - & 4.31 & $\mathrm{C}_{25} \mathrm{H}_{40} \mathrm{O}_{6}$ \\
\hline Verapamil & 52-53-9 & 454.6 & 4.02 & $\mathrm{n}$ & 8.97 & $\mathrm{C}_{27} \mathrm{H}_{38} \mathrm{~N}_{2} \mathrm{O}_{4}$ \\
\hline DEET & $134-62-3$ & 191.27 & 2.42 & $\mathrm{n}$ & -1.37 & $\mathrm{C}_{12} \mathrm{H}_{17} \mathrm{NO}$ \\
\hline Atrazine & $1912-24-9$ & 215.68 & 2.64 & $\mathrm{n}$ & 2.27 & $\mathrm{C}_{8} \mathrm{H}_{14} \mathrm{ClN}_{5}$ \\
\hline Linuron & $330-55-2$ & 249.09 & 3.12 & $\mathrm{n}$ & $12.13 ;-1.04$ & $\mathrm{C}_{9} \mathrm{H}_{10} \mathrm{C}_{12} \mathrm{~N}_{2} \mathrm{O}_{2}$ \\
\hline t-octylphenol & $140-66-9$ & 206.32 & 5.18 & $\mathrm{n}$ & 10.15 & $\mathrm{C}_{14} \mathrm{H}_{22} \mathrm{O}$ \\
\hline Nonylphenol & $104-40-5$ & 220.35 & 6.14 & $\mathrm{n}$ & 10.15 & $\mathrm{C}_{15} \mathrm{H}_{24} \mathrm{O}$ \\
\hline Estrone & $53-16-7$ & 270.37 & 3.62 & $\mathrm{n}$ & 10.25 & $\mathrm{C}_{18} \mathrm{H}_{22} \mathrm{O}_{2}$ \\
\hline $17 \beta$-estradiol & $50-28-2$ & 272.38 & 4.14 & $\mathrm{n}$ & 10.27 & $\mathrm{C}_{18} \mathrm{H}_{24} \mathrm{O}_{2}$ \\
\hline 17 $\alpha$-estradiol & 57-91-0 & 272.38 & 4.14 & $\mathrm{n}$ & 10.27 & $\mathrm{C}_{18} \mathrm{H}_{24} \mathrm{O}_{2}$ \\
\hline Androstenedione & 63-05-8 & 286.41 & 2.72 & $\mathrm{n}$ & not applicable & $\mathrm{C}_{19} \mathrm{H}_{26} \mathrm{O}_{2}$ \\
\hline Estriol & $50-27-1$ & 288.38 & 2.53 & $\mathrm{n}$ & 10.25 & $\mathrm{C}_{18} \mathrm{H}_{24} \mathrm{O}_{3}$ \\
\hline Testosterone & $58-22-0$ & 288.42 & 3.18 & $\mathrm{n}$ & 15.06 & $\mathrm{C}_{19} \mathrm{H}_{28} \mathrm{O}_{2}$ \\
\hline Etiocholanolone & 53-42-9 & 290.44 & 3.93 & $\mathrm{n}$ & 15.14 & $\mathrm{C}_{19} \mathrm{H}_{30} \mathrm{O}_{2}$ \\
\hline Androsterone & 53-41-8 & 290.44 & 3.93 & $\mathrm{n}$ & 15.14 & $\mathrm{C}_{19} \mathrm{H}_{30} \mathrm{O}_{2}$ \\
\hline 17a-ethynylestradiol & $57-63-6$ & 296.4 & 4.11 & $\mathrm{n}$ & 10.24 & $\mathrm{C}_{20} \mathrm{H}_{24} \mathrm{O}_{2}$ \\
\hline
\end{tabular}


Table 2: Properties of the HTI and NF90 membranes.

\begin{tabular}{|c|c|c|}
\hline Membrane & HTI & NF90 \\
\hline Material of the skin layer & Cellulose acetate & Polyamide \\
\hline Average pore diameter (nm) & $0.74^{\mathrm{a}}$ & $0.68^{b}$ \\
\hline Water permeability, $A\left(\mathrm{~L} / \mathrm{m}^{2} \mathrm{hbar}\right)$ & 1.08 & 4.36 \\
\hline Salt permeability, $B\left(\mathrm{~L} / \mathrm{m}^{2} \mathrm{~h}\right)$ & 0.245 & 1.32 \\
\hline \multirow{2}{*}{ Contact angle $\left({ }^{\circ}\right)$} & $64 \pm 3$ & $60 \pm 5$ \\
\hline & $66 \pm 5$ & not applicable \\
\hline
\end{tabular}

${ }^{\mathrm{a}}$ Ref: [14]; ${ }^{\mathrm{b}}$ Ref: [30]. 